\title{
Modern Conveyor Pulleys with Modified End Disc Design, Locking Device \& Gearless Drive
}

\author{
Ramkrushna Chaudhari, A. G. Thakur
}

\begin{abstract}
Nowadays, in order to mine the ore economically, it became necessary to increase the tonnage of mined ore, as well as to improve the method of transporting the ore that is to be mined. Belt conveyors are essential equipment for transferring the material from one place to targeted place and conveyor pulleys are the major component of conveyor system. Such kind of conveyor system needs reliable conveyor pulleys. Different type of conveyor pulleys are used throughout the conveyor system as per their function. In this research, the agenda is on modification of present conveyor pulley design by removing the most common causes of catastrophic fatigue failure which are used for high tension application in mining industry. The target during the research is on improvement of end disc design, elimination keyed connection in between shaft and hub by using locking device. The another development is to use of gearless drive technology for drive pulleys. This is obtained by continuous improvement and strategic standardized process to cater the need of mining application. These modified conveyor pulleys are best suitable for high capacity, high tension long distance conveyors used in mining industry.
\end{abstract}

Keywords: Conveyor pulleys, End disc, locking assembly, gearless drive, turbo disc, Keyless, gearless drive, turbo disc, rotor

\section{INTRODUCTION}

Currently we are using conveyor pulleys manufactured from welded steel but it is developed from fabricated wood and in present also the development is going on. The belt conveyors are extensively used in many industries such as mining, cement, port handling, material handling, fertilizer and many more industries. These industries are continuously demanding that conveying capacity shall be increased significantly. As the capacity of conveyor rapidly increases it will increase the tension on belt and add more load on pulleys, drive system of pulleys. The construction of pulley and drive arrangement shall be modified to accommodate the demand of industry.

Conveyor pulley is heart of the conveyor and plays vital role in reliability and performance of conveying system. The failure of any pulley may result in to breakdown of whole conveyor system. Due to this it is quite serious to select correct design of pulley to keep conveying system operating and meet daily production rate.

Manuscript received on July 20, 2021.

Revised Manuscript received on July 27, 2021.

Manuscript published on July 30, 2021.

* Correspondence Author

Ramkrushna Chaudhari*, Student, M.tech, Mechanical engineering, Sanjivani College of Engineering, Kopargaon, affiliated to Savitibai Phule Pune University, Pune (Maharashtra), India.

A. G. Thakur, Director, Sanjivani College of Engineering, Kopargaon, affiliated to Savitibai Phule Pune University, Pune (Maharashtra), India.

(C) The Authors. Published by Blue Eyes Intelligence Engineering and Sciences Publication (BEIESP). This is an open access article under the CC BY-NC-ND license (http://creativecommons.org/licenses/by-nc-nd/4.0/)
The industries are exceeding convention and expecting high tension customized pulleys, they are called as "Engineered Pulleys". ${ }^{[1]}$ The drive arrangement of $6000 \mathrm{~kW}$ (8000HP) has been normal in today's era. The catastrophic failure pulley may hamper the economical balance sheet of organization and also have consequences on safety.

\section{LITERATURE REVIEW}

CEMA has several revisions to enhance advanced information in the conveyor components. CEMA is accredited by ANSI. The codes and Standards used for designing conveyor pulley are DIN, IS, ISO, BS and CEMA (Conveyor Equipment Manufacturing Association). However, it is a normal for industries to implement in-shop design and manufacturing technique following the standards, but followed by their own experience. Unfortunately, nearly all codes on pulley design do not sufficiently give relation of stresses and deflection. While the CEMA standard specification on pulley design deliberates fatigue life of shaft, it does not include any information on selection of the thickness of shell and diaphragm. CEMA standard is widely used by conveyor manufacturer. ${ }^{[1]}$

The second standard is MHEA (Material Handling Equipment Association) practice allows thin web construction but its expression for examining shell thickness seems rather conventional as it ignores the influence of wrap angle on shell stresses. Apart from this, it joins the shaft deflection with disc stresses, it does not correlate the stresses in shell and disc and their attachment. Moreover, it does not give idea about the tapered hub diaphragm construction. The other codes like IS: 8531-1986, BS 2890 and DIN 22101 provides us the major sizes for pulleys, without stating any basis for dimensions of the separate parts. ${ }^{[2]}$

The nature of the typical failure pattern in conveyor belt pulleys has changed. The paper describes advance and whole analytical system. Using this type of model, the root cause for shell failure trends are identified and, cures demonstrated. The same model is used to validate how shell life can be calculated and verified to plant life at little or no additional cost. The model is fully justified and tested against wear observations and finite element analysis. [5]

To satisfy the expectations of belt conveyor manufacturer the pulleys need to modified. The failure in conveyor pulley leads to complete interruption in system \& causes major loss to organization. The attempt must be to make pulley components more reliable with feasible manufacturing methods. [8]

Published By:

Blue Eyes Intelligence Engineering

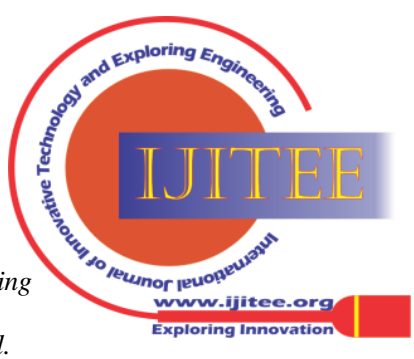


In a typical keyed shaft construction where shocks or reversing loads are to be transmitted, the clearance between key and keyway required for fitting is a critical issue. The impact load causes a continuous vibration and pounding between key and keyway. The catastrophic fatigue failure of pulley shaft may occur due to this pounding. The present project work presents a Keyless coupling. The device provides a complete solution by incorporating all the advantages of interference fits, while making assembly and removal shaft easy. Analysis is performed using ANSYS. The obtained results are compared with standard catalogue values. The standard values are taken from RINGFEDER catalogue. The keyless data is taken from RINGFEDER. Here it has made an attempt in analyzing keyless coupling. From the results it can be concluded that keyless coupling is most suitable. [9]

\section{END DISC DESGN ADVANCEMENT}

The most regular presently used hub and diaphragm construction is shown in fig. 1 a. The disc made of plate is welded to shell and hub. The disc is a gas cut from weldable quality structural steel plate, in which the outer diameter is matching to shell and inner diameter is matching to hub. The hubs are machined from round bar or forged steel blank or weldable steel casting, based on the quality requirement. The hub is welded at the center of disc on both sides to withstand large number of tangential forces. ${ }^{[3]}$ This type of construction includes large amount cyclic bending stresses along with weld inclusions. The increased stress in welded areas leads to catastrophic fatigue failure of pulleys. Weld zones are more prone to higher stress areas. Conveyor pulley is a rotating composite structure operating in dynamic load for every rotation of its parts go through a complete reversal of stresses caused due to the load. This leads to the fatigue in the components. The most common cause of premature catastrophic failure is weld between hub \& disc i.e. fig. 1 a. Welded section reduces the metal fatigue strength.

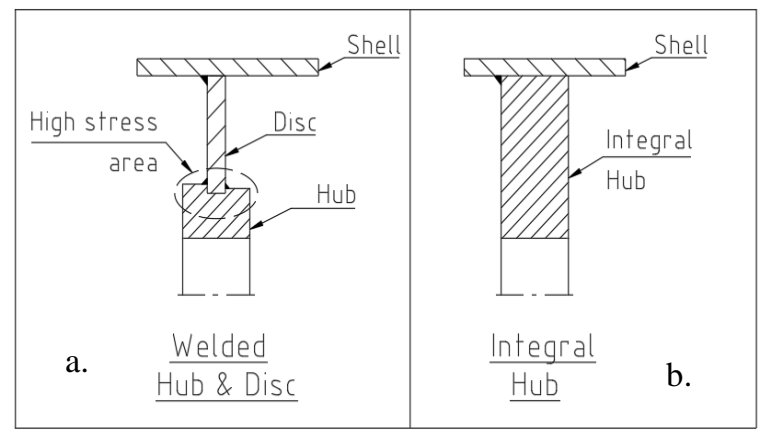

Fig. 1.a Conventional hub \& disc connection Fig. 1.b Advancement by eliminating weld between hub and disc

To avoid the failure of pulley at weld between hub and disc we have taken piecemeal approach to solve this issue and making advancement step by step. To eliminate the weld between hub and disc we can use the same thickness of the hub throughout by elimination of plate disc. In that case higher hub thickness will be used throughout and pulley will become unnecessarily heavy. It increases the stiffness of disc which is extremely undesirable results in additional load on shaft and may lead to failure of shaft. The other problem with this design is that it has higher thickness at weld between shell and hub, quite critical to perform welding. Through penetration of weld is not possible in such case. As the weld does not have sufficient strength again it leads to failure of pulley.

\section{Bending stress flow pattern}

Before moving to other advancement, we will study the nature of stress pattern inside the disc. The bending stress distribution in end disc is shown in fig.2. The bending stress is changing its sign from +ve to -ve magnitude at marked location. At this location the thickness of disc can be considerably reduced which and we can take the advantage of stress crossing through zero without hampering its load capacity. The thickness can be reduced significantly at this point and we can make profile by following stress distribution to maintain constant stresses throughout the end disc. ${ }^{[4]}$

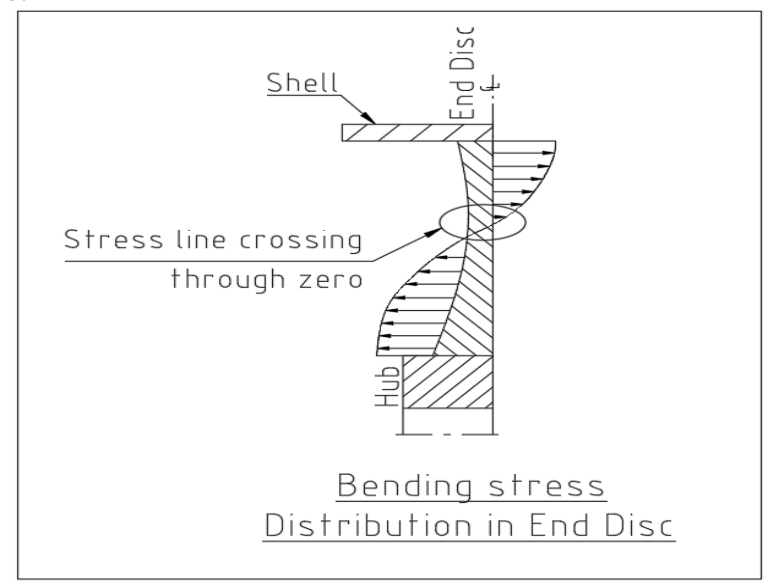

Fig.2 - Bending stress distribution in end disc

The next advancement for hub \& disc design is we can modify the profile of end disc such that the ideal profile similar to turbine shape can take care of amount of bending stress variation. The turbine shape reduces the disc stiffness while optimizing the distribution of end-disc bending stresses. In this case welding is eliminated in between hub and disc by amking a single end disc in which hub will be its integral part. The turbine shaped end-disc can be made from a common metal plate, casting or forging material based on the requirement.

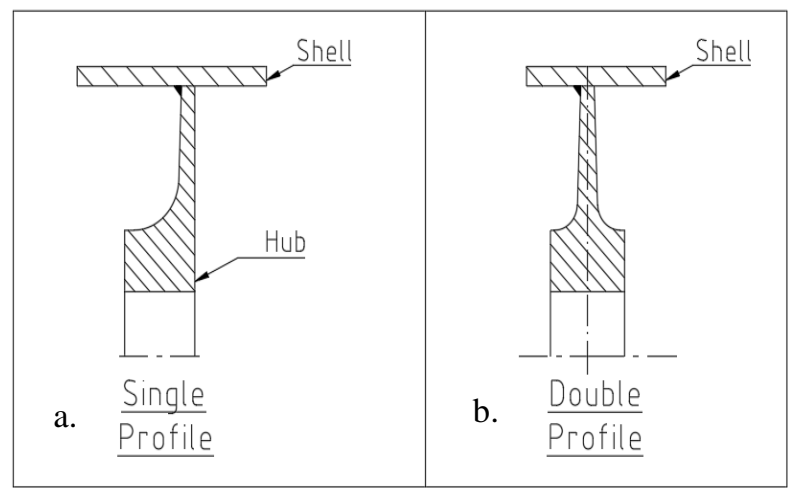

Fig.3 - Turbine shape end disc construction with integral hub, a) Single profile b) Double profile

Published By:

Blue Eyes Intelligence Engineering and Sciences Publication

(C) Copyright: All rights reserved. 
The end disc has higher thickness at inner radius and tapers by reducing thickness towards shell. The end disc looks like single stage turbine wheel hence it is called as turbo-disc or turbo-diaphragm. The end disc has thickest root at inner diameter toward shaft side without welded joint between hub and disc where the tangential, bending stresses are higher in magnitude. This makes the design more desirable by considering the load of pulley. ${ }^{[3]}$ Both single profile and double profile end disc can be used for low duty standard conveyor pulleys. Double profile end disc is preferred over single profile due to its better balancing properties. The turbine shape reduces the disc stiffness while optimizing the distribution of end-dis bending stresses.

But if the pulleys are operating in heavy duty application suffering from extra ordinary forces, the weld between end disc and shell will surely leads to fatigue failure. So we are proposed to shift the position of weld from high stress area to low stress area. This can be achieved by moving the weld inboard of end disc and make weld on rim, refer fig. 4 . The merits of this arrangement is that it has substantial radius at both inside and outside high stress zone. The welding arrangement is quite similar to weld between two same thickness plates welded along periphery. The $\mathrm{T} / \mathrm{J}$ bottom end disc is expensive due to complex shape but this arrangement is best to deal with extra ordinary forces. This profile confirms the stresses all over end disc are constant and have adequate flexibility, less stress concentration. The strength of weld can be increased by providing backing strip to support the weld. The backing strip is tack welded inside the shell and rim of end disc are brought in contact to weld together.

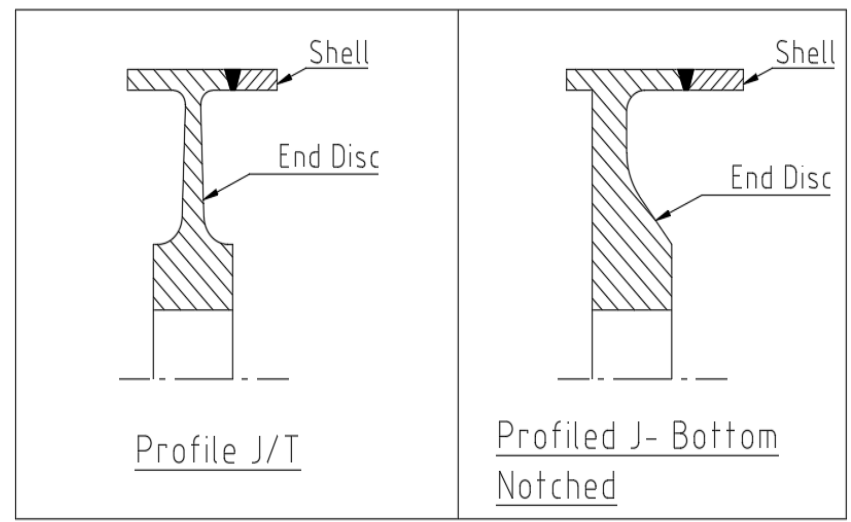

Fig.4 - Turbine shape end disc construction with integral hub $-\mathrm{J} / \mathrm{T}$ bottom type

\section{USE OF LOCKING DEVICE FOR HUB AND SHAFT CONNECTION}

Keyway construction and splined fastening is quite problematic particularly in excess and frequent torque reversal conditions. The pulley is composite structure, which is exposed to tangential and radial stresses. The conveyor pulleys are going through numerous bending \& torsional stresses. The fastened parts undergo micro dislocation and movement which leads to damage of the component. The notch of the keyway seal increases the stress in the shaft and mating component. The power is transmitted along single line of contact in keyed connection arrangement. Fig. 5 shows some of fatigue failure of the hub and shaft keyed construction in shaft failure due to fatigue crack which were operating in rotating machine of mill. Once the key connection is fitted with shaft and mating component it is dreary task to disassemble them. It requires more time and energy to install and removal of keyed construction. The substitute for keyed connection is forced fit (pressure \& heating) to secure position where radial pressure produced due to shaft and hub linking. But disadvantage of this arrangement is that it is quite painful in mounting and dismantling.
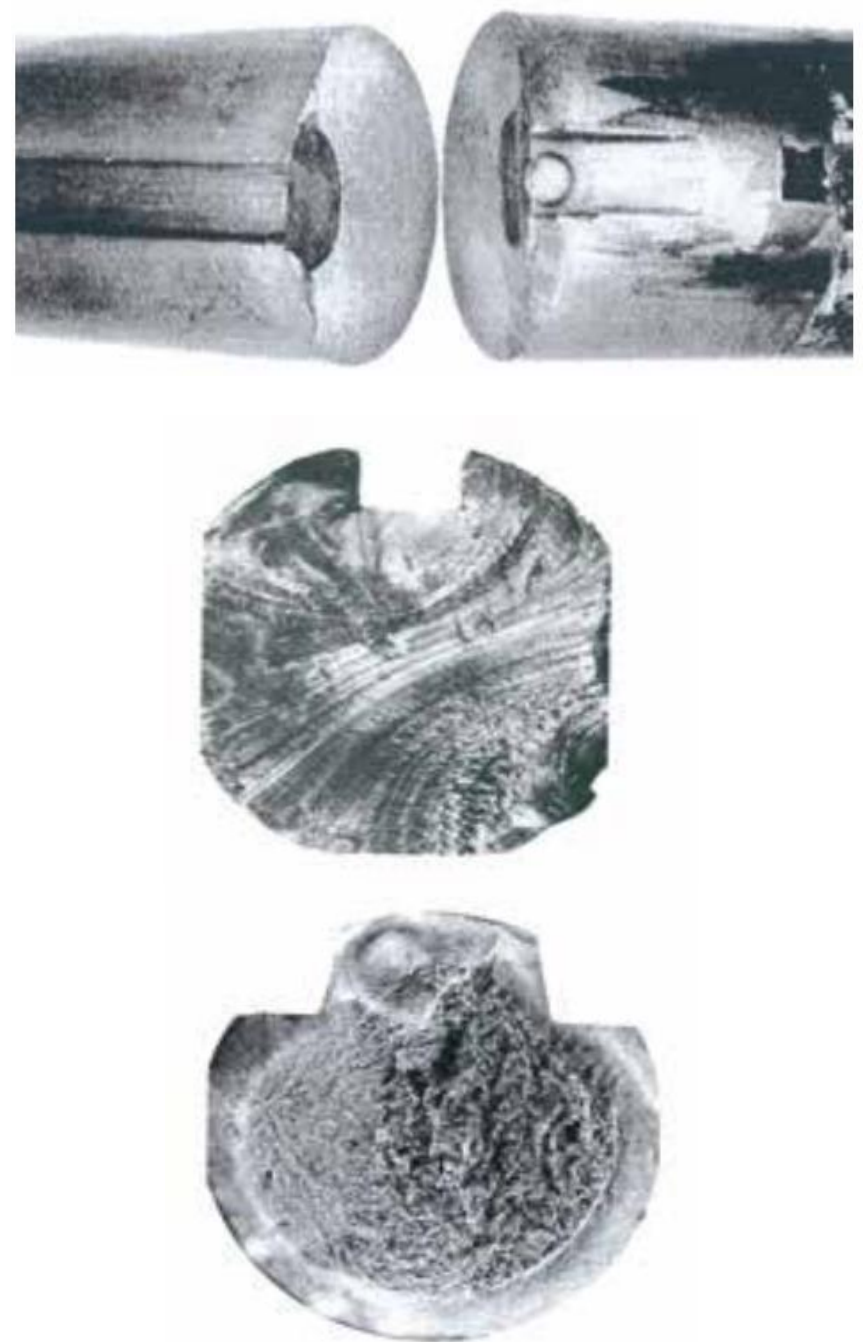

Fig.5 - Shaft failure due to fatigue crack (Heat treated steel C45) (courtesy of ASM International, Metals Handbook, vol.9)

The FEA (fig. 6) shows that the stresses are transmitted along single line of contact in keyed construction. The stresses inside the shaft increases due to presence of keyway. The installation and removal of key is also quite complicated task and consumes more time during manufacturing. ${ }^{[10]}$

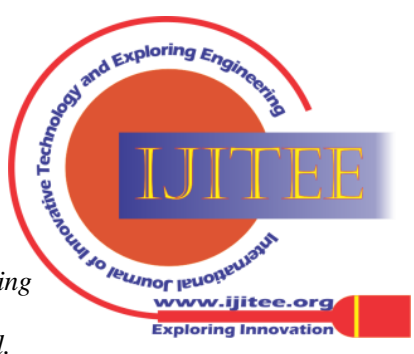




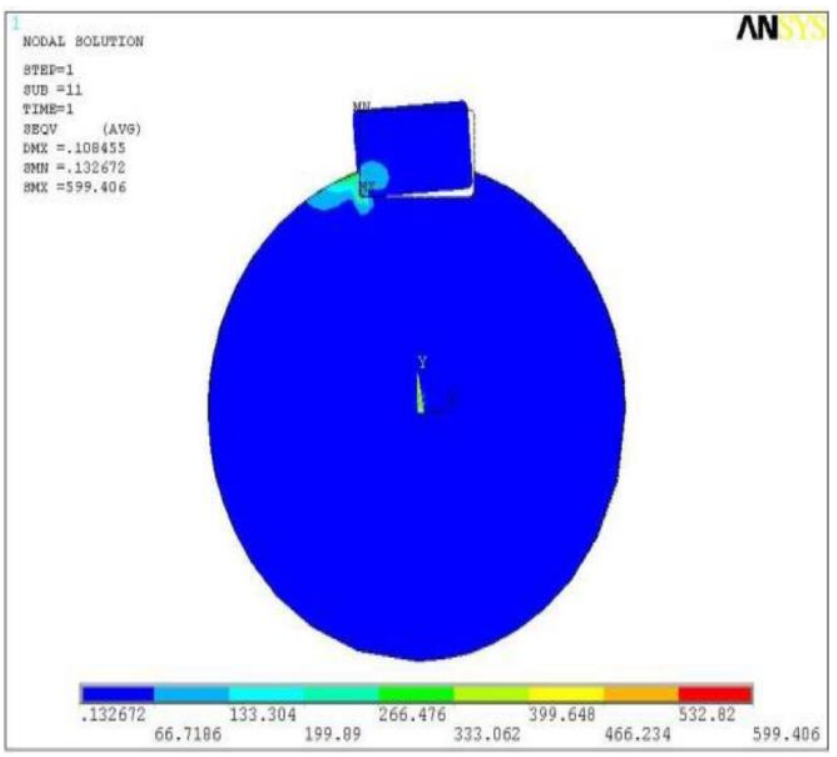

Fig.6 - FEA of Keyed shaft showing stresses transmitted along a single line of contact

\section{Disadvantages of Keyed connection}

- Keyway in the shaft reduces the cross sectional area of shaft and increases stress concentration.

- With keyed construction removal of shaft from pulley tends to damage the pulley body.

- $\quad$ Transmits stresses with single line of contact along the keyway.

- Due to use of keyed connection unnecessarily increases the stiffness in the hub and disc.

- For keyed construction pulleys, welded joint between hub and disc increases the chances of fatigue failure.

To overcome all above disadvantages of keyed connection between shaft and hub, we have searched an alternative solution to keyed connection. We are expecting wear-free way to join shaft components. The Locking device (fig. 7) is the component which to secure position of shaft and hub. The locking device arrangement allows easy removal and refitting of pulleys on shaft. There is no keyway in shaft, and hence no weakening and stress concentration in shaft component. To operate the locking device, just by tightening the locking screw causes increase in outer radius of and reduces the inner radius by creating strong friction grip between shaft and end disc to transmit forces. The contact of shaft with locking assembly subjected to radial compressive pressure whereas hub is subjected to radial outward pressure.

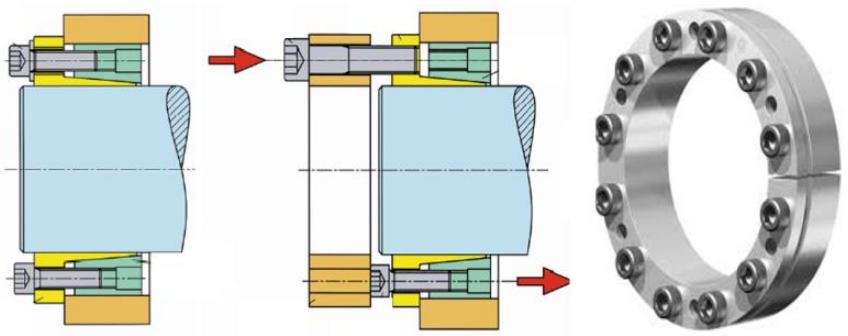

Fig.7 - Locking Device sketch

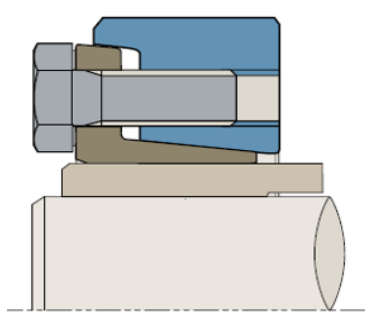

BEFORE

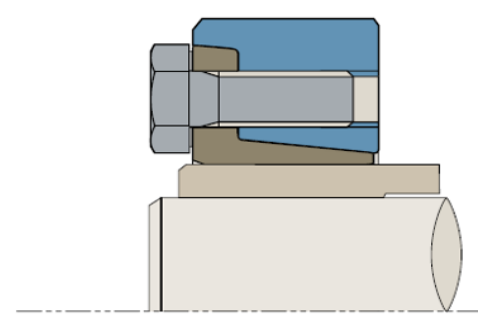

AFTER

Fig.8 - Locking Device connection before and after tightening of locking screws

The locking devices are frictional devices which uses pressure and friction to secure position of shaft and hub. Locking devices use wedge principle to translate the clamp loads from locking screws into radial contact pressure on shaft and end disc. Locking devices join the shaft component by making $360^{\circ}$ contact pressure and creates mechanical interference fit with shaft and mating component. The non-keyed locking device uses pressure and friction to secure the pulley to its shaft. This eliminates the keyway and its stress risers, thereby increasing the shafts load capacity, by as much as $60 \%$. [11]

Fig. 9 shows comparison of stress distribution in keyed and locking device connection. In keyed connection the power is transmitted along single line of contact and key way in shaft reduces the strength of shaft. In case of locking device, it creates $360^{\circ}$ contact with shaft and mating components and transmits stresses in all direction.

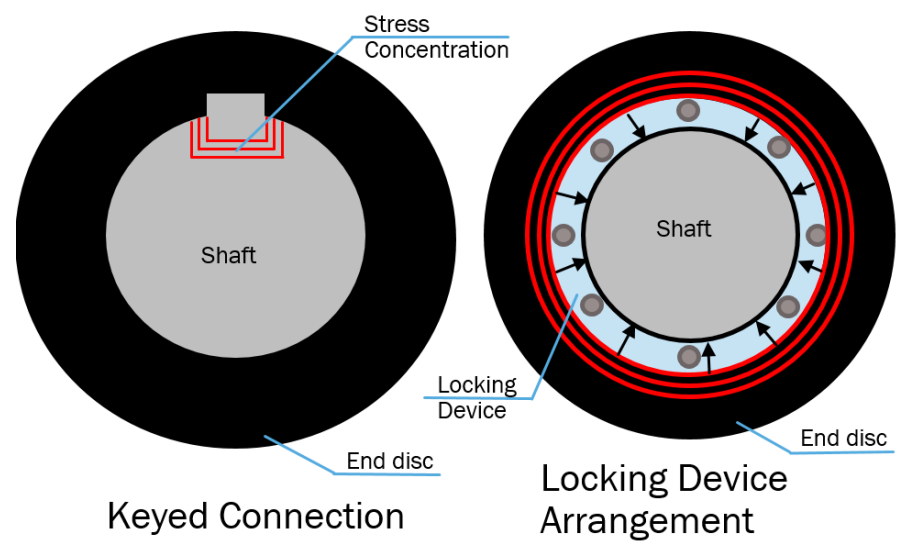

Fig.9 - Comparison of stress distribution in keyed and locking device connection

\section{Advantages of Locking Assembly}

- Eliminate the stress concentration in the shaft

- Transmits stresses with $360{ }^{0}$ Contact with shaft

- Installation \& removal of shaft easy is without damaging pulley body

- Reduces the stiffness in the hub, hence bending moment transferred to shaft through locking assembly will reduce and resulting in lesser stresses in shaft

- $\quad$ Reliable design of pulley

Published By:

Blue Eyes Intelligence Engineering

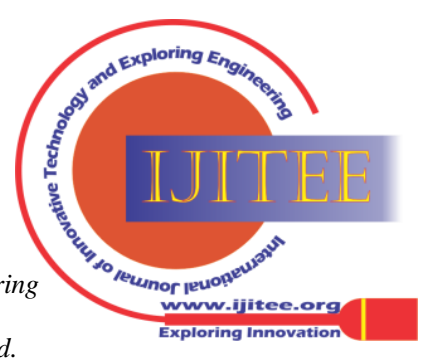




\section{USE OF GEARLESS DRIVE SYSTEM}

In many mining applications, ore quality declining day by day. The belt conveyor operations in hard rock mining are extending over distance more than $16 \mathrm{~km}$ and has to tackle elevation difference of $500 \mathrm{~m}$, while this transferring material at rate of approximately 12000 tph. Newly discovered mines are situated at remote places, pits are getting deeper and underground mines are becoming larger. Such industries expect that the more material must be transported over long distances with the help of conveyors. [12]

In order to achieve the huge volumes and high demands for availability, conveying systems will need to implement the technologies made possible by today's drive system.

Today, for large conveyors gearboxes are used and this system has its own physical limit. For instance, conveyor demands 20,000 kW would require eight traditional drives to meet demand, each of them equipped with $2500 \mathrm{~kW}$ motors. This system has disadvantage that it reduces the reliability due to large number of components and requires large space.

Most of mine sites are in remote locations, they demand for highly reliable equipment that can perform in mining regions. Also, maintenance cost must be within control. However, we need to find out new technology that reduce maintenance costs as a prominent factor while selecting material handling solution. The material handling industries are expecting that the system shall transport more ore over longer distance \& have minimized maintenance as well as operating cost, must have precise and powerful drive solution with fewer components. The solution shall energy efficient.

Now, to meet the demands of present industry we propose to use new high performance generation of gearless drives. Long distance conveyors with high tension throughout and steep elevation differences require a sufficient amount of power. When the demand of power exceeds more than certain MW per pulley, Gearless drive system are the perfect solution. The drive system of a belt conveyor has to provide the required speed and torque at any point of operation. This is ensured by using the appropriate converter technology and considering the engineering of the system with an integrated approach.

\section{Arrangement of gearless drive system}

The gearless drive system overcomes the restrictions attributed to gear reducers and this gearless arrangement is simple, robust and easy to maintain. The belt designs are also upgraded day by day and today can manufacture strongest belts that can withstand higher stresses resulting from high drive power. This is the perfect opportunity to shift from conventional drive system to modern gearless drive technology to meet the demand high tension long distance conveyors situated at remoted locations in mines.

In conventional system, we need motor, coupling between motor to gearbox, gearbox, coupling between gearbox to drive pulley and finally the power is transmitted to drive shaft of drive pulley. But, this system contains more mechanical components and requires more maintenance. The failure of any single component leads to break-down of whole conveyor system \& industry has to bear large losses.

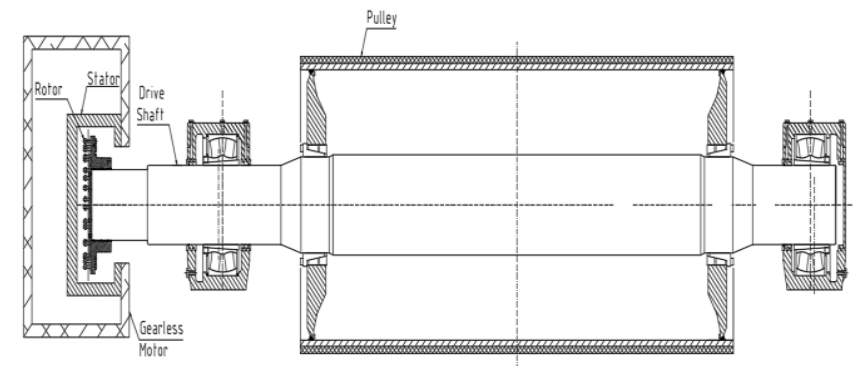

Fig.10 - Arrangement of gearless drive on drive pulley

In gearless drive system, the motor is directly in installed at the end of shaft on drive side. Each motor has stator and rotor for performing its operation. As change is made inside the stator, the opposite poles attract the poles of rotor. This magnetic field of stator rotates; the rotor is forced to rotate with it. In gearless drive technology, we are installing rotor mounted of drive end of pulley shaft and this arrangement is inserted inside the stator of motor (Fig. 10). The power generated by motor is directly given to rotor and rotor will transmit this power to the shaft of drive pulley to perform its operation. The rotor mounted on pulley shaft acts as integral part of drive system. By using such type of arrangement we can eliminate the gearbox, coupling at motor to gearbox and coupling at gearbox to pulley shaft. By eliminating this mechanical component, the reliability of drive system increases. As there is few moving parts, the power losses will be less. The maintenance required would be less compared to conventional gearbox system. This arrangement is highly recommended for heavy duty long distance conveyors.

Comparison between conventional drive and gearless drive (Fig. 11) shows that the conventional geared drive need more components, such as bearings and couplings. As it increases the number of components the availability and reliability decreases. At the same time for gearless pulley requires fewer moving parts obviously fewer spare parts are required for the gearless solution and reliability increases significantly. In such way we can try to find out the efficiency of both drive solutions. As a result of friction energy is converted into heat in the conventional components i.e gearbox, couplings. This energy is lost and cannot be used to move the drive pulley and reduces the efficiency. As a consequence, for a gearbox generally 2-4\% power loss must be taken into account (depending on the particular gearbox design). [12] The gearless drive transmits the power directly to the drive pulley. In gearless drive system reduces number of operating components, their maintenance and increases reliability.

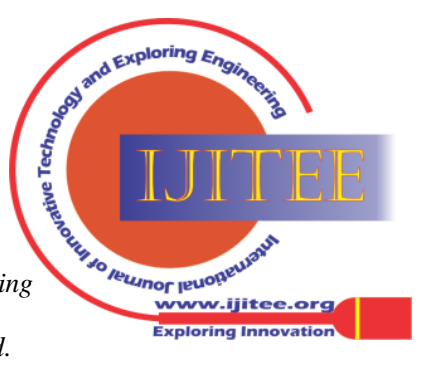




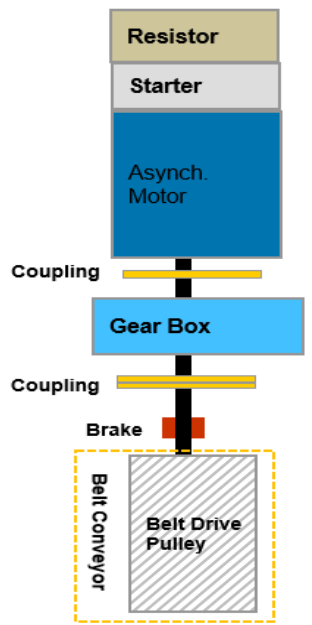

a. Conventional drive

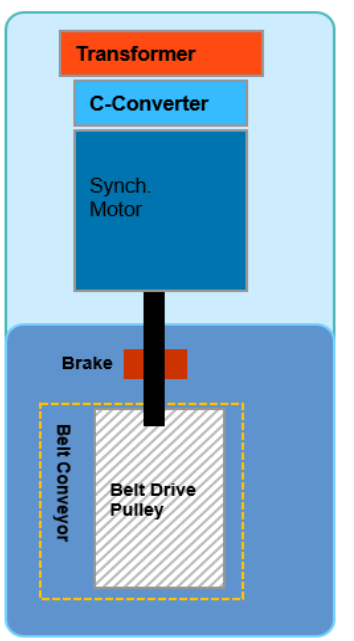

b. Gearless drive
Fig.11 - Comparison of conventional \& Gearless drive

\section{Advantages of Gearless drive for Conveyor Pulleys}

- Higher Efficiency as Mechanical losses are eliminated due to elimination of gearbox and coupling

- Low Maintenance \& Operating Cost through the use of robust components.

- System is More Compact \& higher reliable

- Reduction in Noise levels achieved by eliminating Gear reducers

- Increases energy efficiency by about $4 \%$

- Reduce the potential for mechanical breakdowns by using more robust components

\section{Limitations of Gearless drive for Conveyor Pulleys}

- Gearless drive arrangements are costly in low power applications

\section{RESULT COMPARISON OF CONVENTIONAL} AND MODERN CONVEYOR PULLEY

\begin{tabular}{|c|c|c|}
\hline Parameters & $\begin{array}{l}\text { Conventional } \\
\text { Pulley }\end{array}$ & $\begin{array}{l}\text { Modern Design } \\
\text { Pulley }\end{array}$ \\
\hline $\begin{array}{l}\text { Hub \& Disc } \\
\text { Design }\end{array}$ & $\begin{array}{l}\text { Hub \& disc is } \\
\text { separate component } \\
\text { joint together by } \\
\text { welding }\end{array}$ & $\begin{array}{l}\text { Modified end disc } \\
\text { has hub integrated } \\
\text { hub. Eliminated } \\
\text { weld between hub \& } \\
\text { disc }\end{array}$ \\
\hline $\begin{array}{l}\text { Fatigue } \\
\text { failure }\end{array}$ & $\begin{array}{l}\text { Due to presence of } \\
\text { weld between hub } \\
\text { and disc leads } \\
\text { catastrophic fatigue } \\
\text { failure }\end{array}$ & $\begin{array}{l}\text { Eliminated the most } \\
\text { common cause of } \\
\text { fatigue of failure by } \\
\text { eliminating weld } \\
\text { between hub and } \\
\text { disc. }\end{array}$ \\
\hline $\begin{array}{l}\text { Connection } \\
\text { between } \\
\text { shaft and hub }\end{array}$ & Keyed & Locking device \\
\hline $\begin{array}{l}\text { stress } \\
\text { concentration } \\
\text { \& stresses }\end{array}$ & $\begin{array}{l}\text { Presence of higher } \\
\text { stresses and stress } \\
\text { concentration due } \\
\text { to keyway }\end{array}$ & $\begin{array}{l}\text { Less stresses and } \\
\text { stress concentration } \\
\text { as there is no } \\
\text { keyway in shaft } \\
\text { component }\end{array}$ \\
\hline $\begin{array}{l}\text { Power } \\
\text { transmission }\end{array}$ & $\begin{array}{l}\text { along the keyway } \\
\text { which single line of } \\
\text { contact }\end{array}$ & $\begin{array}{l}\text { Power is transmitted } \\
\text { in all direction along } \\
360^{\circ} \text { contact with } \\
\text { mating component }\end{array}$ \\
\hline
\end{tabular}

(c) Copyright: All rights reserved.
Published By:

Blue Eyes Intelligence Engineering and Sciences Publication

\section{CONCLUSION}

This paper the use of all above developments of conveyor pulley design which results in removal of weld between hub and disc and eradicates most common cause of pulley failure. The adapted end disc design allows smooth distribution of stresses. The use of locking assembly eliminates keyed connection between shaft and hub and surges the strength of shaft by as much $60 \%$ as per BIKON locking assembly catalogue. The installation and removal of shaft will be easy without damaging pulley body, which saves time of assembly. The reliability of joint has improved by $40 \%$ due to use of locking assembly. The gearless drive is most suitable where power requirement is more than $3 \mathrm{MW}$ due to its huge cost. By implementing gearless drive, the energy efficiency improved by $4 \%$. Among all, the designed conveyor pulleys prove that these are most suitable solution for conveyor pulleys to encounter the demand of present industries of bulk material handling. It gives highly reliable, maintenance free solution.

\section{REFERENCES}

1. Conveyor Equipment Manufacturer's Association, "Belt conveyors for bulk materials" 6th edition,ch, 8, The New CEMA Book.

2. "Recommended practice for troughed belt conveyors", by "Mechanical Handling Engineer's Association - MHEA"

3. Ishwar G Mulani and Mrs. Madhu I Mulani, "Engineering Science and application design for belt conveyor", Madhu I. Mulani, 2002.

4. Vinit Sethi and Lawrence K. Nordell, "Modern Pulley Design Techniques And Failure Analysis Methods", Proceedings of SME Annual Meeting \& Exhibit, Peno Nevada, USA, Feb. 15-18, 1993.

5. Terry King, "The function and mechanism of Conveyor Pulleys drums", paper presented at beltcon $4^{\text {th }}$ conference, Johnnesburg, 1985.

6. Terry King: "Belt conveyor pulley design - why failures ?", bulk solid handling, The international journal of storing, handling and transporting bulk, solid handling, The international journal of storing, handling and transporting bulk, vol 6, No-6. Oct / dec 1986

7. Gys van Zyl, Abdulmohsin Al-Sahli, "Failure Analysis of Conveyor pulley shaft", volume 1, issue 2, April 2013, at ELSEVIER

8. B.E. Lloyd," The Design of Conveyor Pulleys”, at SAIMH.

9. Kishor H.P., Raghu T, “ Design Anlaysis of Keyless Coupling”, Vol. 1, Issue 1, pp:937-43), Month : April 2014- September 2014.

10. Research paper on "Failure Analysis of Conveyor pulley shaft", by Gys van Zyl, Abdulmohsin Al-Sahli at ELSEVIER.

11. Catalogue of locking assembly make -Bikon, Bikon corp. \& Ringfeeder, Ringfeeder.com

12. https://www.agg-net.com/news/abb-gearless-conveyor-drive-forwider-range-of-motors - ABB user manual for gearless drive system.

13. M. Cobes, D. Diescherl, T. Rösch, " Increasing Availability through advanced Gearless Drive Technology", Siemens.com/mining.

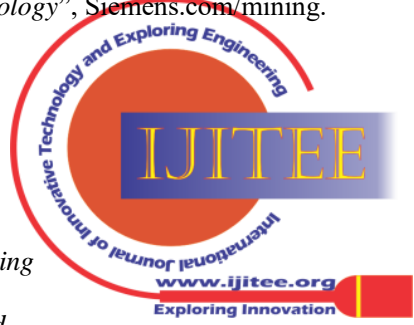




\section{AUTHORS PROFILE}

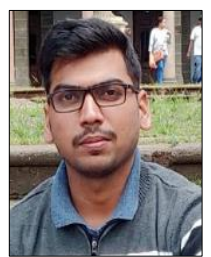

Ramkrushna Chaudhari, M. Tech, Design Engineering, Sanjivani College of Engineering, Kopargaon, Savitribai Phule Pune University, Pune, India. Research \& Design Engineer -Thyssenkrupp Industries India Pvt. Ltd., Pune, India ramkrushna.chaudhari@outlook.com

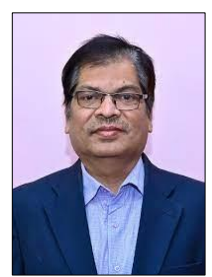

Dr. A. G. Thakur, Ph.D, Mechanical Engineering, $32+$ years of teaching experience, 20+ Paper Published, 25+ Paper presented in Conferences, Director, Sanjivani College of Engineering, Kopargaon, Savitribai Phule Pune University, Pune, India. 